\title{
Thematic Progression in Iraqi Scientific Articles
}

\author{
Marwa Alaa' Al-Bazzaz \\ Asst. Instructor \\ Al-Mansour University College \\ Aws Nasri Al-Shajlawi \\ Asst. Instructor \\ Al-Imam Al-Adham University College
}

\begin{abstract}
This paper investigates the use of thematic progression in scientific articles written by Iraqi EFL learners of English language, in the hope that it would be helpful for teachers of writing non-native speakers students. This study employs the descriptive qualitative method to analyze the collected data. Since thematic progression plays an important role in structuring and organizing discourse and it is considered as a bridge that connects sentence level to the discourse level to produce a cohesive text. So this paper deals with the analysis of professional scientific essays written by Iraqi EFL learners in two different disciplines (Medicine and Engineering). Daneš thematic progression patterns are used as a model of analysis in this study. The findings of the study shows that simple linear is the most used one while derived and split is less used one. This study concludes that the researchers faced a difficulty in presenting a well organized text.
\end{abstract}

Keywords: Thematic Progression, Theme, Rheme, Coherence, Medical and Engineering Texts.

\section{Introduction}

Thematic progression is defined as the flow of information in a sentence from Theme to rheme to achieve communicative effectiveness in a message (Eggins 2004: 82). Theme, according to Haliday (1994:38), is "what the message is concerned with, the point of departure of what the speaker is going to say" in a clause. On the other hand, rheme is the part that contains the actual new information to be conveyed. One can present an article which is considered as well-organized unity and with clear line of developed information by focusing on thematic progression to present textual and interpersonal meanings in a coherent way (Butt et al. 2000: 142).

Thematic progression can say something about the text genre. Genre is defined according to Swales (1981:10) cited in (Nowgu and Bloor 1991:370) "a more or less standardized communicative event with a goal or set of goals mutually understood by the participants in that event and occurring within a functional setting". Thematic progression refers to the ways in which texts develop the ideas they present. It is, thus, thematic progression concerned with how the themes and rhymes of a text are sequenced.

Thematic organization of the text is closely related to the discourse coherence, so text can be defined to its semantic coherence. The linguistic term thematisation which presents the given and new information, usually the given information will be on the first part of the utterance which is known as the theme and the new information is in the right side of the utterance which is known as the rheme of the sentence. So one can say that text connexity is related to the choice and ordering of themes and how it is connected to the hyper theme of the whole text. According to this, Daneš (1974), who has divided thematic progression, is divided into four types: linear, constant, derived and split themes which are considered as the skeleton of the text.

In accordance with what has already been said, we have examined professional genres of scientific (medical and engineering discourse) to highlight the use of thematic progression in EST texts (i.e., English for Science and Technology) which are considered as a branch of ESP written by Iraqi researchers who have learned English as foreign language, since language varies as its function in different situations . To present a cohesive text, one needs to show the understanding of how to use thematic progression. It is something very essential to present a cohesive text. 


\section{Data}

This paper is based on the analysis of 10 articles. The data comprise of 35,000 words in specialized, medical and engineering essays written by non-native speakers of English (i.e., Iraqi researches). These articles have been published in Kufa Med Journal and Basrah Journal of Engineering Science. Temporally speaking, the analyzed data are from 2012 to 2015 there is as good as no change in the format as the research concerned.

\section{Theoretical Model}

The most well known and used model in the analysis of thematic progression is Daneš (1974). By this term he meant "the choice and ordering of utterance themes, their mutual concatenation and hierarchy, as well as their relationship to the hyperthemes of the superior text units (such as the paragraph, chapter...), to the whole text, and to the situation" (114). He has distinguished four different types of thematic progression. These are Simple Linear, Constant Themes, Derived Theme, and Split Rheme.

\subsubsection{Simple Linear}

As demonstrated by Daneš (1974:118), it is shown to present the most basic or elementary type of thematic progression. In this pattern, the rheme of a given utterance becomes the theme of the subsequent utterance and so on. In other words, the given information in the rheme position of the previous clause becomes the theme of the next clause As shown below:

T1
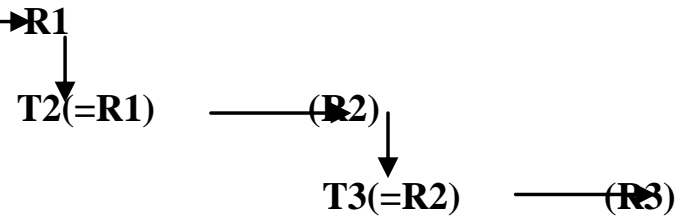

(1)Concrete behavior/ is stimulated by elastic-plastic model with a five parameter William Warke failure surface. The failure surface/ consists of a conical shape with curved meridians and noncircular base sections (Jwad and Assi,2013:19).

\subsubsection{Constant Theme}

Constant progression is where the same theme appears in a series of utterances(Wie 2015: 181). The characteristic feature of this progression is that the same theme appears repeatedly, or we can say the same theme repeated in each sentence of the text to make it coherent as illustrated by:

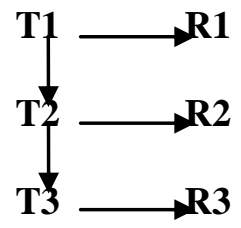

(2) Pfaff et al. [1]/ studied the bubble pump with a lithium bromide-water vapor absorption cycle. They/ developed a mathematical model using the manometer principle to evaluate the bubble pump performance. They / found that the pumping ratio is independent of the heat input.(Faisal et. Al, 2014:77)

\subsubsection{Derived theme}

Daneš demonstrates derived progression as "the particular utterance themes are derived from a "hypertheme" (of a paragraph, or other text section) in which the choice of the derived utterance themes will be controlled by various special usage of the presentation of subject-matter" (Daneš 1974: 120). He envisages derived progression as way of reminding readers of the main topic or of keeping them focused". (Hawes 2015:95).

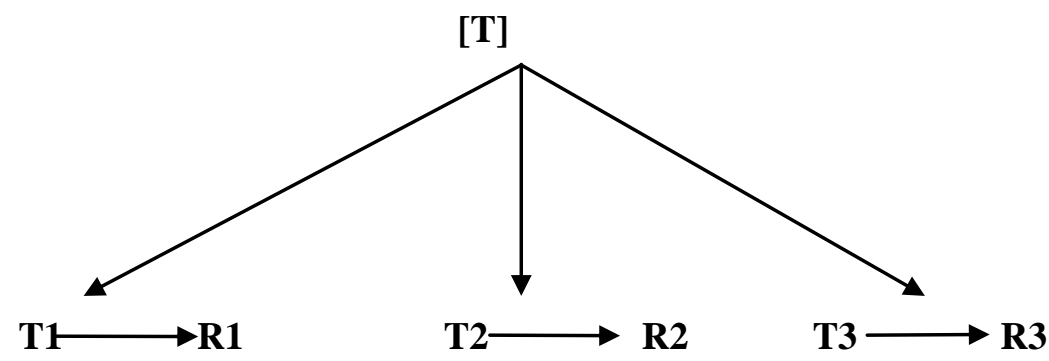


(3)The water pollution of both types (natural and industrial)/ is the most important problems faced by most countries of the world, but the amount of pollution/ is different from one country to another. However, the major pollution of water/ comes from the population and the industrial basis. (Al-Shemari and Abdulhussein 2013: 140)

\subsubsection{Split Rheme}

The typical characteristic of this progression is that the rheme of the first clause would be divided into two parts, each part will be the theme of the subsequent clauses. (Nwogu and Bloor, 1991: 373). So, one can say that in this progression we have double rheme and each rheme will be the starting point of separate thematic progression as shown below:

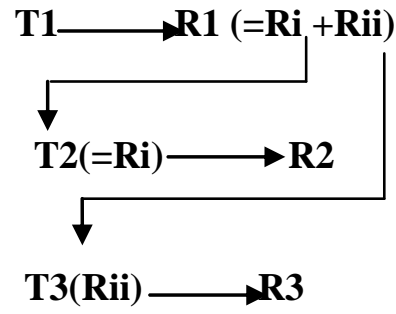

(4)There/ are many theories that discuss the causes of migraine. The cortical spreading depression(CSD) theory/ suggests that migraine is a disease of the brain such as angina is a disease of the heart. Another theory/ is the vascular theory introduced by Wolff which suggests that migraines result from the widening of blood vessels surrounding the brain . (Qasim 2013: 1)

The problem is that Daneš model does not seem to cover up all the different types of thematic progression. If it is related to the end of new topic and another one begins which is related to the cohesion of sentence level to the cohesion of the text level as whole. We need to talk about the "breaks" (Hawes 2015) (i.e., non-participant themes) which are usually known as marked themes. Examples of breaks are (WH and polar interrogatives, verb groups, it predicates, there predicates, bound clauses and annex themes.

The difference between thematic progression and break is that the former is a matter of a link between the first constituent and the next one. While the latter (i.e., breaks) do the opposite, forming the end of progression or the start of a new one. It makes a connection between the sentence level and the text level coherence.(Hawes 2015: 96).

\section{Methodology}

After giving a brief review of Daneš thematic progression types. The next step was to use the qualitative descriptive method to analyze and describe the collected data. As I mentioned previously, I collected these articles from two different scientific journals. The analytical procedure was to break down into clauses, and then determining the theme and rheme and identifying the type of progression used by the researchers and calculating the number of each type. After presenting the findings in a table that shows the occurrence of each type, I present a conclusion to show how the researchers use thematic progression in their writing.

\section{Results and Discussion}

Medicine (Med) and engineering (Eng) discourse. The percentage indicates that simple linear (46.8\%) is the most used one by the researchers which they tend to use it in explanation of their research papers. On the other hand, one notice that the less frequent one is the split where only seven instances are found in all the ten articles. The following table indicates the frequency of occurrence of each type in all the ten articles. 
Table The Frequency of Occurrence of Daneš TP Types

\begin{tabular}{|l|l|l|l|l|l|l|}
\hline Text & Linear & Constant & Derived & Split & Total & $\%$ \\
\hline Med.1 & 8 & 4 & 0 & 0 & 12 & 8.2 \\
\hline Med.2 & 3 & 6 & 0 & 0 & 9 & 6.1 \\
\hline Med.3 & 1 & 3 & 1 & 1 & 6 & 4.1 \\
\hline Med.4 & 3 & 2 & 1 & 2 & 8 & 5.4 \\
\hline Med.5 & 4 & 6 & 2 & 1 & 13 & 8.9 \\
\hline Eng.1 & 7 & 9 & 5 & 0 & 21 & 14.3 \\
\hline Eng.2 & 7 & 17 & 2 & 1 & 27 & 18.4 \\
\hline Eng.3 & 3 & 6 & 5 & 0 & 14 & 9.5 \\
\hline Eng.4 & 8 & 7 & 3 & 0 & 18 & 12.3 \\
\hline Eng.5 & 10 & 3 & 3 & 2 & 18 & 12.3 \\
\hline Total & 81 & 63 & 22 & 7 & 173 & 100 \\
\hline$\%$ & 46.8 & 36.4 & 12.7 & 4.04 & 100 & \\
\hline
\end{tabular}

The table shows that engineering articles tend to use derived progression more than medical articles. The most used one by both medical and engineering articles are simple linear and constant progression. Here are some of the observed points in the examined articles.

1. The overuse of constant is quite common in academic writing. Since most of the paragraphs on the 'introduction', 'method' and 'results are descriptive ones, so, constant is considered the natural vehicle for the descriptive paragraph and this helps to understand the high frequency of its use.

(5)Sathe (2001) [3], studied theoretically and experimentally the vapor-lift pump that used for the distribution BPVARS. He used methyl alcohol (methanol) as a tested fluid. He found that the frequency of pumping action (fluid pulse out of the bubble pump per unit time) increases with increase in the heat input. (Faisal et. al. 2014: 77).

2. The misuse of punctuation marks which led to poor coherent and un understandable text.

(6)There /was no correlation between maternal and cord blood serum ferritin ( $\mathrm{r}=0.2)$ (fiq 1). There / was no correlation between maternal serum ferritin and maternal serum iron or per cent saturation of the iron capacity or between cord blood serum ferritin and cord serum iron or per cent saturation of the iron binding capacity. (Dosh, 2012:77)

If we take a look at (T2) in the second line, we notice that the writer repeats the conjunction or more than once without using any the target language. The text is presented in a way as if it were literal reality translated from Arabic to English.

3. Poor understanding of the use of connectors between clauses or sentences presents a rather weak cohesive text.

(7)As mentioned earlier the water quality in general/ depends on the chemical, physical and biological characteristics of water. The quality of water/ depends on the concentrations of inorganic constraints, which includes elements such as (Nitrates and Boron Fluoride) and the group of rare or scarce elements (such as Calcium, Lead, Manganese, Iron, Copper, Zinc, Nickel and Chromium)[6]. The water quality/ is important regarding to regardless of its water availability. The water/ may be valid for a particular use and unsuitable for other[7].

4. New material presented as new theme.

(8)Tigris River/ runs through the city of Baghdad in the mature stage forming river meandering and a number of islands due to the decrease of river velocity and increase in sedimentation. Tigris River/ divides Baghdad into two parts (Karkh and Rusafa). Dijla River with a (300) km length/ meets the Tigris River south of east of Baghdad. (Al-Shemari and Abdulhussein, 2013:147)

If we take a look at line 4, we could see that Dijla river is used as the theme while it should be previously introduced in the rhemes. It is perfectly justifiable to talk about Dijla river but the problem is to be thematized, the writer need to set a ground for the new information by mentioning it in the previous rhemes. 


\section{Random use of breaks}

(9) Diabetes mellitus (DM)/ is a group of metabolic disturbance, characterized/ mainly by hyperglycemia resulting from defects in the secretion or action of insulin. (Hussein 2012:224)

(10) If we take a look at line 2 , we see clause reduction notified by (characterized). It is worth noting that this type of breaks is very rare to diagnose, while there is a lack in the WH interrogative and annex interrogative and bound clauses. These breaks are used frequently in evaluation or in raising a problem, but it tends to be absent in these articles. It and there as predicates are mainly used to express evaluation or a conclusion of a result which connects a paragraph to the text level as whole:

(11) Generally, it/ was found that there /are reductions in the shear strength of soil when the pore fluid/ is changed from distributed water to solutions of salts or raw sewage. Also, it /was found there is a change in the calculated values of permeability. (Saeed et al. 2015: 50)

6. Derived and split are numerically shown less frequent and in most cases almost absent. The researchers tend to use them in the Abstract, and they tend to be used to present classification in expository paragraphs.

(12) Two case studies/ are considered for non-linear finite element analysis. Case No. 1/ refers to the experimental program conducted by Nilson and Losberg, Case No.2 /refers to Singh and Kaushik. (Jwad and Assi 2013:20).

7. Linear progression is used to present the logical progression of text and sharpens the reader's appetite for the presented information.

(13) In diabetes, the slow non-enzymatic covalent attachment of glucose to hemoglobin /increases the amount in the $\mathrm{HbAl}(\mathrm{HbAlc})$ fraction relative to non-glycated adult hemoglobin $(\mathrm{HbA} 0)$. These/ fractions can be separated by chromatography. (Abdul-Hussein 2012:225).

\section{Conclusion}

To recapture things, we have tried to give a detailed account of the analysis of thematic progression and scientific articles written by Iraqi researchers. As for thematic progression, teachers need to put a great focus on how to use the types of thematic progression and when to use it. Specially, when L1 has a structure different from the target language. Also, there is a need to put specific courses in colleges directed to ESP to pinpoint the important tools and ways to present a cohesive text, especially when the writers come from a very low-level of English. So, they need courses designed for them to show the them the basic functions of functional grammar and which type of thematic progression could provide an explicit way of understanding to the reader. Also, they have to master the non-participant theme which help them to have a solid ground in writing, for example, to have a good start of new topic and when to end and when the discourse changes its direction.

\section{Reference}

Butt, D., Fahey, R., Feez, S., Spinks, S. \& Yallop, C. (2000).Using functional grammar: An explorer's guide (rev. ed.)

Daneš, F., 1974. Functional sentence perspective and the organisation of the text. In: Daneš, F. (Ed.), Papers on Functional Sentence Perspective. Academia, Prague, pp. 106-128.

Eggins, S. (2004). An introduction to systemic functional linguistics. London: Continuum.

Halliday, M.A.K. (1994). An Introduction to functional grammar (2nd ed.). Beijing: Foreign Language Teaching and Research Press.

Hawes, T. (2015). Thematic Progression in the Writing of Students and Professionals. Augsburg: Germany: Ampersand 93-100.

Nwogu, K.N., \& Bloor, T. (1991). Thematic progression in professional and popular medical texts. In E. Ventola (Ed.), Functional and systemic linguistics: Approaches and uses (pp. 369-384). Berlin \& New York: Mouton de Gruyter.

Wei, J. (2015). Theme and Thematic Progression in English Writing Teaching. Journal of Education and Practice, Vol. 6, No.21 pp. 178-188.

Yang, X. (2008). Thematic progression analysis in teaching exploration writing. English Language Teaching,1(1), 29-33. 


\section{Appendix}

Abdul Hussein, M. (2012). Validity of HbA1c for Screening and Diagnosis of Diabetes Mellitus. Kufa Med Journal Vol.15, No. 1

Hatef, M. (2012). Burn in Pregnancy ( A Prospective Study of 60 Pregnant Burned Woman With Thermal Injuries). Kufa Med. Journal Vol. 15, No. 1

Dosh, B. (2012). Relationship of Maternal and Cord Blood Iron Stores. Kufa Med. Journal Vol., 15, No. 1

Qasim, A. (2013). Acupuncture for Migraine Prophylaxis. Kufa Med Journal. Vol. 16, No. 2

Al-Mohammadi, M. and Mohammad, Z. (2012). A Study of Some Physical Changes in Patients with Inherited Thrombosthenia. Kufa Med. Journal. Vol. 15, No.1

Manea, E. et. al., (2014). Evaluation of the Performance of Steel in Reinforced Concrete by Electrochemical Methods. Basrah Journal for Engineering Sciences, Vol. 14, No. 2.

Al-Shemari, H. and Abdulhussein, I. (2013). Study the Effect of Baghdad City on the Tigris River Water Pollution. . Basrah Journal for Engineering Sciences, Vol. 14, No. 2.

Rashid, M. (2015). Modeling of Self-Organization Fish School System by Neutral Network System. Basrah Journal for Engineering Sciences, Vol. 15, No. 1.

Faisal, S. et. al. (2014). Expermental Study of Thermal Bubble Pump. Basrah Journal for Engineering Sciences, Vol. 14, No. 2.

Jawad, D. and Assi, L. (2013). Nonlinear Finite Element Analysis of Reinforced Concrete Corner Joints Subjected Opening Moments. Basrah Journal for Engineering Sciences, Vol. 14, No. 2. 